\title{
Assessment of the Egyptian gynecologists' clinical attitude and practice concerning route of hysterectomy
}

\author{
Abstract \\ Objective: To assess the attitude of Egyptian gynecologists towards the route of \\ hysterectomy in benign pathologies.
}

Materials and methods: A survey was supplied to a sample of gynecologists in Egypt either in conferences or electronically to be filled and returned.

Results: In this study the addressed gynecologist' age below or equal to 48 years were $50.6 \%$ and those above 48 years were $49.4 \%$. Majority of gynecologists had more than 12 yearexperience $(59.3 \%)$. The abdominal route with subtotal hysterectomy type represented $(71.5 \%)$. This prevalence was attributed to fear of complications of total hysterectomy in about $(90.1 \%)$. Majority of gynecologists had no adherence to postoperative follow up $(98.3 \%)$

Conclusions: Subtotal hysterectomy is the prevalent type of hysterectomy in Egypt owing to fear of complications and medico-legal issues. Regular training courses are required to encourage gynecologists in Egypt to practice total hysterectomy with safe approaches and fewer complications.

Keywords: Hysterectomy, Total/subtotal, Attitude/practice, Egyptian gynecologists, Survey
Volume 8 Issue 4 - 2019

\author{
Ayman Shehata Dawood,' Hesham \\ Mohamed Borg, ${ }^{2}$ Salwa Abdelmageid Atlam ${ }^{3}$ \\ 'Lecturer of Obstetrics and Gynecology, Tanta University, Egypt \\ ${ }^{2}$ Assistant professor of Obstetrics and Gynecology, Tanta \\ University, Egypt \\ ${ }^{3}$ Assistant professor of Public Health, Tanta University, Egypt
}

Correspondence: Ayman Shehata Dawood, Lecturer of Obstetrics and Gynecology, Tanta University, Egypt, Tel +201020972067, Email Ayman.dawood@med.tanta.edu.eg

Received: April 01, 2019 | Published: August 05, 2019

\section{Introduction}

Hysterectomy is the second most common operative procedure performed worldwide following cesarean section. The influence of hysterectomy on women's health and how to perform hysterectomy safely are matters of diverse debate. The influences of hysterectomy on maternal health are linked to physical, economic, sexual, and psychological consequences. Safe hysterectomy routes depends mainly on either surgeon's and/or patient's choice. Surgeon's choice is based mainly on expertise, practice, and attitude of the surgeon while the choice of patient is mainly based on proper counseling and personal beliefs rather than the strength of evidence. ${ }^{1}$

Although subtotal hysterectomy has some theoretical benefits regarding shorter operative time, better pelvic floor function and better sexual performance, randomized clinical trials did not support supracervical hysterectomy., ${ }^{2,3}$ Thakar et al. ${ }^{4}$ included 279 women in a randomized trial to assess urinary, bowel and sexual function in total and subtotal groups. They found no significant different between the two groups regarding studied parameters. Shorter hospital stay (5.2days versus 6days) and lower rate of postoperative fever (6\% versus 19\%) in subtotal and total groups respectively. Cyclical bleeding occurred in the subtotal group by a rate of $7 \%$.

Similarly, Gimbel H et al., ${ }^{5}$ demonstrated a $20 \%$ rate of cyclical vaginal bleeding following subtotal hysterectomy. They reported a higher incidence of urinary incontinence in the subtotal group $(18 \%$ versus $9 \%$ ) without impact on quality of life or sexual function. ${ }^{5}$ Another study reported post hysterectomy cyclic bleeding occurring in $11 \%$ to $17 \%$ of cases. ${ }^{6}$ A Cochrane review was conducted to evaluate which is superior total versus subtotal hysterectomy. They concluded that the existing data do not support superiority of one type over the other regarding sexual, bladder, or bowel function. ${ }^{7}$
On the same side, the American College of Obstetricians and Gynecologists found that supracervical hysterectomy is not superior to total type and gynecologist must screen patients carefully for cervical or uterine neoplasia prior to choosing subtotal approach. ${ }^{8}$ Despite these issues, few studies were found to assess the attitude and practice of gynecologists towards the route of hysterectomy plus the factors affecting surgeon's choice of hysterectomy type. In Egypt, no statistics were found to address the prevalence of both types of hysterectomy among Egyptian gynecologists and the factors affecting their preference of one type over the other. For these reasons, this study was designed to assess the previously mentioned issues.

\section{Materials and methods}

Study design: Cross sectional survey study.

Study time: It was done from September 2016 to December 2016.

Study sample: It was a simple random sample.

Sample size calculation: It was calculated using Epi-info program version 6 with the total number of Egyptian Specialist in Obstetrics \& Gynecology was 16608 (Statistics of Egyptian Medical Syndicate, December 2016). The least number of participants should be 163 with an $80 \%$ confidence limit, 50\% expected frequency and 5\% confidence level.

Study tool: The data were collected through a constructed selfadministered questionnaire sheet. The questionnaire was validated with a readability and framework validation by eight gynecologists of varying seniority in the specialty. The comments and suggestions of these readers were considered and agreement obtained for the last edition of the questionnaire. The first part of the questionnaire included sociodemographic data as age, gender, residence, scientific degree, 
experience years and place of work. The second part composed of 9 questions regarding attitude and practice of the gynecologist regarding type of hysterectomy in the form of:

1. Number of hysterectomies done/year

2. Type of hysterectomy done

3. Causes behind type of hysterectomy chosen

4. If there was cervical cancer screening program

5. Counseling of patients prior to hysterectomy,

6. Screening after hysterectomy

7. Number of cases of cancer cervix detected after subtotal hysterectomy/year

8. Indications of hysterectomy and

9. If patient was satisfied with the type of operation.

The third part was the participant recommendations. The questionnaire is presented in appendix 1.

\section{Methods of data acquisition}

The questionnaire was distributed at wide variety of Egyptian Obstetrics and Gynecology conferences which were held during study duration. Moreover, questionnaire was sent to gynaecologists electronically via emails, WhatsApp, Twitter, and Facebook. The gynecologists who participated in questionnaire filled it and returned it to us. The filled in questionnaire was collected and statistically analysed.

\section{Study parameters}

The studies parameters were the prevalence of each type of hysterectomy in Egypt, the factors affecting preference, attitude and practice among Egyptian gynecologists to route and type of hysterectomy, prevalence of counseling prior to hysterectomy and postoperative screening for cervical cancer.

\section{Results}

The returned questionnaires were 172 complete sheets with a response rate $86 \%$. The enrolled gynecologists $(n=172)$ in this study were nearly of equal distribution regarding age, male to female ratio and residence. The great majority were working at general hospitals (56.4\%), most of participants were Diploma qualified (44.8\%) while Master degree was found in 66 participants (38.4\%). the demographic characteristics of participants were shown in Table 1.

The predominant type of hysterectomy was the subtotal type whatever the age, gender, years of experience, or residence. The difference was the degree of qualification where in MD degree more total hysterectomies were preferred. Another difference was found in hospital type where total hysterectomy was preferred to the subtotal hysterectomy among university, educational and armed forced hospital. Age in general has no significantly affect the choice of hysterectomy route, but young gynecologists with experience less than 12 ssyears were more operating total hysterectomies due to their enthusiasm to adhere to evidence based experiences and knowledge. These distributions were explained in Table 2 .

The indications of hysterectomies were abnormal uterine bleeding
(97.1\%); myomas (77.91\%), pelvic pains $(65.12 \%)$ and adenomyosis $(25.60 \%)$ were the main indications. These indications were presented in Table 3.

Table I Characteristics of study participants

\begin{tabular}{|c|c|c|}
\hline Characteristics & No. & $\%$ \\
\hline \multicolumn{3}{|l|}{ Age groups } \\
\hline$\leq 48$ years & 87 & 50.6 \\
\hline$>48$ years & 85 & 49.4 \\
\hline \multicolumn{3}{|l|}{ Gender } \\
\hline Male & 82 & 47.7 \\
\hline Female & 90 & 52.3 \\
\hline \multicolumn{3}{|l|}{ Years of experience } \\
\hline$\geq 12$ years & 102 & 59.3 \\
\hline$<12$ years & 70 & 40.7 \\
\hline \multicolumn{3}{|l|}{ Residence } \\
\hline Urban & 88 & 51.2 \\
\hline Rural & 84 & 48.8 \\
\hline \multicolumn{3}{|l|}{ Hospitals } \\
\hline University Hospital & 22 & 12.8 \\
\hline Educational Hospital & 14 & 8.1 \\
\hline Insurance Hospital & 18 & 10.5 \\
\hline Armed Forces Hospital & 4 & 2.3 \\
\hline General Hospital & 97 & 56.4 \\
\hline Private Hospital & 17 & 9.9 \\
\hline \multicolumn{3}{|l|}{ Degree of qualification } \\
\hline Diploma & 77 & 44.8 \\
\hline Master & 66 & 38.4 \\
\hline Medical Doctor & 29 & 16.9 \\
\hline
\end{tabular}

The causes of preference of subtotal hysterectomy over total one was mainly due to fear of complications of total one and the medicolegal issues related to these complications $(90.1 \%)$, the fear of urinary injuries eg. Ureteric injuries were the cause in 133 participants (77.3\%), the patient desire for sexual function was found in 113 participants (65.7\%). Other causes were presented in Table 4.

Asking the participants about counseling of patients prior to hysterectomy, the follow up of cases after subtotal hysterectomies and the programs applied for follow up were explained in Table 5. Most gynecologists $(84.9 \%)$ didn't counsel patients prior to hysterectomy. The great surprise was that nearly all gynecologists (98.3\%) denied the adherence to cervical cancer screening programs after subtotal hysterectomies. The numbers of cancer cervix cases detected were very few due to shortage of follow up programs. The detection rate of cervical cancer was $30.2 \%$. The recommendations in the last sections were to increase availability of screening programs for cervical cancer (14.54\%), and regular workshops for safe total hysterectomy $(79.65 \%)$. 
Table 2 Distributions of types of Hysterectomies according to characteristics of study participants

\begin{tabular}{|c|c|c|c|c|}
\hline & $\begin{array}{l}\text { Subtotal } \\
\text { Hysterecto my } \\
\text { N(\%) I 23(7।.5) }\end{array}$ & $\begin{array}{l}\text { Total } \\
\text { Hysterectomy } \\
\text { N(\%)49(28.5) }\end{array}$ & $\begin{array}{l}\text { Total N(\%) } \\
\text { I72(100) }\end{array}$ & $\mathbf{X}^{2}(\mathbf{P})$ \\
\hline \multicolumn{5}{|l|}{ Age } \\
\hline$\leq 48$ years & $62(71.3)$ & $25(28.7)$ & $87(50.58)$ & $.005(.942)$ \\
\hline$>48$ years & $61(71.8)$ & $24(28.2)$ & $85(49.42)$ & \\
\hline \multicolumn{5}{|l|}{ Gender } \\
\hline Male & $55(67.1)$ & $27(32.9)$ & $82(47.7)$ & $1.515(.218)$ \\
\hline Female & $68(75.6)$ & $22(24.4)$ & $90(52.3)$ & \\
\hline \multicolumn{5}{|l|}{ Years of experience } \\
\hline$\geq 12$ years & $78(76.5)$ & $24(23.5)$ & $102(59.3)$ & $28.7032(0.00)^{*}$ \\
\hline$<12$ years & $25(35.7)$ & $45(64.3)$ & $70(40.7)$ & \\
\hline \multicolumn{5}{|l|}{ Residence } \\
\hline Urban & $58(65.9)$ & $30(34.1)$ & $88(51.2)$ & $2.776(0.096)$ \\
\hline Rural & $65(77.4)$ & $19(22.6)$ & $84(48.8)$ & \\
\hline \multicolumn{5}{|l|}{ Hospitals } \\
\hline University Hospital & $\mathrm{I}(4.5)$ & $2 \mathrm{I}(95.5)$ & $22(12.8)$ & FEI I $2.767(.000)^{*}$ \\
\hline Educational Hospital & $\mathrm{I}(7 . \mathrm{I})$ & $13(92.9)$ & $14(8.1)$ & \\
\hline Insurance Hospital & $15(38.3)$ & $3(16.7)$ & $18(10.5)$ & \\
\hline Armed Forces Hospital & 0 & $4(100)$ & $4(2.3)$ & \\
\hline General Hospital & $92(94.8)$ & $5(5.2)$ & $97(56.4)$ & \\
\hline Private Hospital & I4(82.4) & $3(17.6)$ & $17(9.9)$ & \\
\hline \multicolumn{5}{|l|}{ Degree of qualification } \\
\hline Diploma & $77(100)$ & 0 & $77(44.7)$ & $96.979(.000)^{*}$ \\
\hline Master & $45(68.2)$ & $2 \mathrm{I}(3 \mathrm{I} .8)$ & $66(38.4)$ & \\
\hline Medical Doctor & $\mathrm{I}(3.4)$ & $28(96.6)$ & $29(16.9)$ & \\
\hline
\end{tabular}

*significant FE:fisher's exact test.

Table 3 Indications of Hystrectomy

\begin{tabular}{lll}
\hline Indication & No & $\%$ \\
\hline Abnormal uterine bleeding & 167 & 97.1 \\
Myomas & 134 & 77.91 \\
Pelvic pain & 112 & 65.12 \\
Endometriosis/Adenomyosis & 44 & 25.6 \\
\hline
\end{tabular}

\section{Discussion}

The aim of this survey was to detect the most common hysterectomy route preferred by Egyptian gynecologists and if there were relation to age, gender, experience years or the place of work. Although the sample size was small, this survey is considered the first survey in Egypt to evaluate the preference, attitude and practice for the route of hysterectomy among Egyptian gynecologists. Egyptian gynecologists preferred subtotal hysterectomy more than total one for many reasons. The most common reasons were fear of complications $(90.1 \%)$ particularly urinary tract injuries $(77.3 \%)$. The other complications that lead to superiority of subtotal hysterectomy were fear of stump carcinoma, wound infection, vaginal shortening and stump dehiscence. ${ }^{9}$ World wide gynecologists favor subtotal hysterectomy due to its lower complication rates and little sexual function impairment. They remove transformation zone to minimize the risk of cervix cancer. ${ }^{10,11}$

Recently evidence denoted that there is no significant difference between subtotal and total hysterectomies regarding complications (eg, infection; blood loss; urinary tract, bowel, or vascular injury) and post-operative outcomes (eg, sexual function, urinary function, or bowel function). ${ }^{7,8,12,13}$

Zekam et al., ${ }^{14}$ conducted a survey study to estimate the attitudes and practice of American gynecologists regarding total versus subtotal abdominal hysterectomy. A questionnaire on physicians' attitudes and practice regarding total versus subtotal hysterectomy was mailed to 
1647 gynecologists with response rate was $51.2 \%$. They found that most of responders $(45 \%)$ preferred total hysterectomy to minimize risk of cervical cancer. Subtotal hysterectomies were done due to surgical difficulty with change of procedure. Most surgeons (63\%) didn't counsel their patients regarding the route of hysterectomy. ${ }^{14}$

Table 4 Reasons of choosing Subtotal Hysterectomy among gynecologist

\begin{tabular}{lll}
\hline Causes & No. & $\%$ \\
\hline Little experience with total hysterectomy & 28 & 16.3 \\
No experience with total hysterectomy & 90 & 52.3 \\
Fear of complications of total hysterectomy & 155 & 90.1 \\
Fear of urinary injuries & 133 & 77.3 \\
Time of operation & 101 & 53.7 \\
Patient sexual function & 113 & 65.7 \\
Patient request & 74 & 43 \\
Financial causes & 52 & 30.2 \\
Lack of resources & 18 & 10.5 \\
\hline
\end{tabular}

Table 5 Postoperative follow up and care after subtotal hysterectomy among the studied patients

\begin{tabular}{|c|c|c|}
\hline & No. & $\%$ \\
\hline \multicolumn{3}{|c|}{ - Did you counsel patients prior to hysterectomy? } \\
\hline Yes & 26 & 15.1 \\
\hline No & 146 & 84.9 \\
\hline \multicolumn{3}{|l|}{ - Did you follow cervical cancer screening program? } \\
\hline Yes & 3 & 1.7 \\
\hline No & 169 & 98.3 \\
\hline \multicolumn{3}{|c|}{ - How many cases of cancer cervix you detected after } \\
\hline \multicolumn{3}{|l|}{ subtotal hysterectomy / year? } \\
\hline None & 120 & 69.8 \\
\hline I-5 cases & 42 & 24.4 \\
\hline$>5$ cases & 10 & 5.8 \\
\hline \multicolumn{3}{|l|}{ Recommendations of participants } \\
\hline No recommendations & 10 & 5.81 \\
\hline Screening programs for cancer cervix & 25 & 14.54 \\
\hline Regular workshops for safe total hysterectomy & 137 & 79.65 \\
\hline
\end{tabular}

Analysis of the current survey results denoted that whatever age, residence, or gender, subtotal hysterectomy was the preferred type among Egyptian gynecologists. The differences were present regarding qualification degree where MD degree gynecologists preferred total hysterectomy over the subtotal one. Another surprising issue was the years of experience where we found that young gynecologists with less than 12 year-experience preferred total hysterectomy to subtotal one due to their link to recent evidence based knowledge and enthusiasm. The most astonishing results were the shortage of counseling prior to hysterectomy, absence of strict follow up programs following subtotal hysterectomies and low detection rate of cancer cervix. Similar results were also reported by Anderson et al, ${ }^{15}$ in Danish population where $6.6 \%$ of patients after total hysterectomy adhered to screening programs. ${ }^{15}$

The clinical implications from this study are the importance of counseling prior to hysterectomy with explanation of hazards and benefits of each type, the importance of screening for cancer cervix after subtotal hysterectomy, increasing the adherence to evidencebased practice and utilize young gynecologists enthusiasm to minimize wide prevalence of subtotal hysterectomy. Also the recommendations of participant were valuable regarding holding regular workshops for safe total hysterectomy and increase the availability of screening programs for cancer cervix.

The strength of this study was based on its adherence and contact to wide range of gynecologists from different age, experience, residence, and hospitals. Also it is the first survey to address these topics in Egypt. The limitations of this study were the small sample size of participants.

\section{Conclusion}

Subtotal hysterectomy was the most preferred type among Egyptian gynecologists. Many factors were beyond this attitude as fear of complications and especially urinary tract injuries. According to this study, neither counseling nor screening programs for detection of cervical dysplasia or cancer cervix were followed. Larger survey studies are required to assess Egyptian gynecologists' attitude towards the route of hysterectomy.

\section{Acknowledgments}

None.

\section{Conflicts of interest}

The author declares there are no conflicts of interest.

\section{References}

1. Sutton C. Hysterectomy: a historical perspective. Ballieres Clinical Obstetrics \& Gynaecology. 1997;11(1):1-22.

2. Johns A. Supracervical Versus Total Hysterectomy. Clinical Obstetrics and Gynecology. 1997:40(4):930-913.

3. Scott JR, Sharp HT, Dodson MK, et al. Subtotal hysterectomy in modern gynecology: a decision analysis. Am J Obstet Gynecol. 1997;176(6):11861192.

4. Thakar R, Ayers S, Clarkson P, et al. Outcomes after total versus subtotal abdominal hysterectomy. N Engl J Med. 2002;347(9):1318-1325.

5. Gimbel H, Zobbe V, Andersen BM, et al. Randomised controlled trial of total compared with subtotal hysterectomy with one-year follow up results. BJOG. 2003;110(12):1088-1098.

6. Ghomi A, Hantes J, Lotze EC. Incidence of cyclical bleeding after laparoscopic Supracervical hysterectomy. J Minim Invasive Gynecol. 2005;12(3):201-205.

7. Aarts JW, Nieboer TE, Johnson N, et al. Surgical approach to hysterectomy for benign gynaecological disease. Cochrane Database of Systematic Reviews. 2015;12(8):CD003677.

8. Kristen AM, Samantha FB. American College of Obstetricians and Gynecologists' Committee on Gynecologic Practice. Choosing the Route of Hysterectomy for Benign Disease. 2017;701:10-25. 
9. Agdi M, Al Ghafri W, Antolin R, et al. Vaginal vault dehiscence after hysterectomy. J Minin Invasive Gynecol. 2009;16(3):313-317.

10. Redburn JC, Murphy MFG. Hysterectomy prevalence and adjusted cervical and uterine cancer rates in England and Wales. British Journal of Obstetrics and Gynaecology. 200;108(4):388-395.

11. Pouwels NS, Brito LG, Einarsson JI, et al. Cervix removal at the time of hysterectomy: factors affecting patients' choice and effect on subsequent sexual function. Eur J Obstet Gynecol Reprod Biol. 2015;195:67-71.

12. Lethaby A, Ivanova V, Johnson NP. Total versus subtotal hysterectomy for benign gynaecological conditions. Cochrane Database Syst Rev. 2012;18;(4):CD004993.
13. ACOG Committee. Opinion No. 388 November 2007: supracervical hysterectomy. Obstet Gynecol. 2007;110(5):1215-1217.

14. Zekam N, Oyelese Y, Goodwin K, et al. Total versus subtotal hysterectomy: a survey of gynecologists. Obstet Gynecol. 2003;102(2):301-305.

15. Andersen LL, Møller LM, Gimbel HM. Low adherence to cervical cancer screening after subtotal hysterectomy. Dan Med J. 2015;62(12):A5165. 